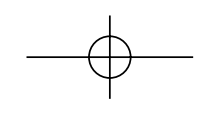

\title{
9 \\ Disjunctive Theories of Perception and Action
}

\author{
David-Hillel Ruben
}

There are many different ways in which to state something that might accurately be called a disjunctive theory of perception, but by the disjunctive theory of perception, I will mean this biconditional: ${ }^{1}$

(1) It looks to $S$ that $\mathrm{p}$ iff either (a) $\mathrm{S}$ sees or perceives that $\mathrm{p}$ or (b) it merely looks to $S$ as if that . $^{2}$

I have expressed the theory in terms of fact-perception rather than object-perception, but nothing in what follows depends on the details of this particular statement of the theory. In truth, the theory might better be described as a disjunctive theory of how things look, or of experience: experience is either perceptual or hallucinatory (I disregard cases of illusion). But the theory is often described in the literature as a disjunctive theory of perception, although perception is merely one of the disjuncts. The theory addresses a traditional problem of perception; hence its more common name.

The idea of the theory is that its looking to a person that there is something that is so is made true either when he perceives that it is so or when it merely looks to him that it is so. The theory is not about conceptual priority, for 'the left-hand side' concept of how things look is conceptually prior to the 'right-hand side' concept of how they merely look. The point of the theory is to deny that 'left-hand side' statements about how things look to a person or about a person's experiences are to be understood as introducing reports of a single type of mental state common to both

I wish to think the editors of this volume, but especially Adrian Haddock, who caused this chapter to be much better than it otherwise would have been. Haddock suggests another way in which I might express my view: the idea of an event embraces items of three different kinds: actions, mere events, and intrinsic events. We might say that, on my view, the kind EVENT is a determinable, and the kinds ACTION, MERE EVENT, and INTRINSIC EVENT are its determinations. In this terminology, event in the wide sense is the determinable, EVENT; event in the narrow sense includes two of its determinations.

1 My statement of the theory is an amalgam of several such statements. See Child (1992: 145-9); Martin (2004: 37-89); Hinton (1973); Snowdon (1980-1: 175-92); and McDowell (1982: 455-79). The last two are reprinted in Dancy (1988).

2 The left-hand side of the biconditional could also be expressed as: 'S experiences that p'. 
perception and hallucination. If statements about how things look introduce anything about mental states at all, they introduce a disjunction of two types of mental states, each one introduced by one of the 'right-hand side' disjuncts.

It is, of course, too strong to say that these two disjunct states, perception on the one hand and hallucination on the other, share nothing in common. Since they are, ex hypothesi, perceptually indiscriminable, they must share at least these two features in common: the features of being perceptually indiscriminable from a veridical perception and of being perceptually indiscriminable from a hallucination (since each is also perceptually indiscriminable from itself). But what is meant to be true is that there is no significant or fundamental type (various statements of the theory express this somewhat differently) to which they both belong, and in virtue of which they are perceptually indiscriminable. ${ }^{3}$

Statements of the disjunctive theory of perception move rather too quickly between two ideas, both of which appeared above, which we might call the ideas of 'disjunctiveness' and 'lack-of-commonality'. Here are just two examples:

Disjunctive theorists... urge that there is nothing literally in common between ... a case of veridical perception and ... a case of hallucination... (Lowe 2000: 145)

The disjunctive theory of perception claims that we should understand statements of how things appear to a perceiver to be equivalent to statements of a disjunction... and that such statements are not to be viewed as introducing a report of a distinctive mental event or state common to these various disjoint statements. (Martin 2004: 37)

The ideas of disjunctiveness and lack-of-commonality are put forward as if they are almost equivalent ideas, or anyway as if each one logically follows from the other.

Is the disjunction that lends its name to the theory intended to be an inclusive or exclusive disjunction? It seems clear that the intention is for the disjunction to be exclusive: one is either having a veridical perception or merely a hallucination, but not both. Indeed, the meaning of each disjunct excludes the applicability of the other disjunct. To have a veridical perception is not to be having a hallucination and conversely. To that extent, the exclusivity of the disjunction is trivially true; it follows from the meaning of the words in the disjuncts.

On the other hand, Martin's minimalist characterization of the hallucination disjunct - that all that can be said about a hallucination is (a) that it is something that is perceptually indistinguishable from a veridical perception - would seem to make the disjunction inclusive, since a veridical perception is also perceptually indistinguishable from itself (see Martin 2004: 48). The minimalist account of the second disjunct

3 Although there is a lot of work to be done in clarifying this idea; see Martin (2004). The above formulation denies that there is some significant feature of both of the token experiences, the veridical perception and the hallucination, a significant feature that they both share. Here is another, similar, although not equivalent, way in which one might make the point, but which relies on the idea of numerical identity of a single token across possible situations: there is no veridical perception which could have been a hallucination, and there is no hallucination which could have been a veridical perception. But in discussion of the disjunctive theory of perception and that of action, I will use the first formulation, in terms of two tokens and the existence or not of a single significant mental type true of them both. 
that Martin defends needs an additional idea in order to be adequate: (b) the idea of non-identity to a veridical perception as well. A hallucination is something that is perceptually indistinguishable from but not the same as a veridical perception. With (b) added, the disjunction will be exclusive. However, if Martin requires that the minimalist characterization of the second disjunct experience be one that is available to the subject's awareness, that adequate characterization is not available, since the very point of perceptual indiscriminability is that one may not be able to tell by introspection whether or not his experience is or is not identical to a veridical perception.

Just what is the relationship between these two ideas, that of disjunctiveness and lack-of-commonality? They certainly are not equivalent. It is obvious that there are exclusive (and a fortiori, inclusive) disjunctions which do have a common element. It is true that ' $\mathrm{p} \mathrm{v} \neg \mathrm{p}$ ' is an exclusive disjunction which has no common element, but on the other hand '(p\&q) v ( $\neg$ \&\&q)' is an exclusive disjunction whose disjuncts do have a common element, viz. ' $\mathrm{q}$ '. So even if 'hallucination or veridical perception' is read as an exclusive disjunction, one cannot infer from that fact to the failure of a common element between them. Equally, and even more obviously, failure of a common element does not argue to exclusivity of disjunction: ' $\mathrm{p} v \mathrm{v}$ ' is a disjunction whose disjuncts have no common element, but it is not an exclusive disjunction-both disjuncts could be true.

When one reflects on the point of the disjunctive theory of perception, it seems that it is the idea of the lack-of-commonality and not the idea of exclusive disjunctiveness which bears the weight of the theory. The core thought of the disjunctive theory depends on the idea of no-feature-in-common-to-both. There is no single fundamental type of state, for example how things look to one, such that being in that state is or is part of the truth-maker for both veridically perceiving and hallucinating. (The biconditional should be read from right to left.) Disjunctiveness is, in any event, only a surface, syntactic feature of a sentence, as surely as we have known since Nelson Goodman's (2005) work on grue.

Sometimes a perceiver cannot tell whether he is the subject of a veridical perception or of a hallucination. That this is so is the basis for many formulations of scepticism. But even if a theory of perception cannot answer scepticism, it ought to be able to offer some account of how confusion, doubt, or error in perception can arise. Other theories of perception claim to be able to do this. If there were something common to veridical perception and hallucination, and if the only difference between them were the absence or presence of some yet further feature F (suppose F is not an observable property), then doubt, error, or confusion can be given this explanation: the subject is experiencing whatever is common to both veridical perception and hallucination, so that can't help him distinguish which sort of experience he is having, and he can't tell whether the experience he is having has F or not, since $\mathrm{F}$ is not an observable property. So the perceiver might be in doubt or confused about which kind of experience it is of which he is the subject.

But how can a theory that denies the commonality assumption explain perceptual error, doubt, or confusion? Martin says that the only mental characterization of a hallucinatory experience (beyond what might be said about experience in general) is that it is an experience that is perceptually indistinguishable from 
a veridical perception. That is not to explain doubt or confusion, merely to redescribe it. There is, on this view, no explanation at all for perceptual doubt and error at the epistemological level, although surely there will be some straightforward physical account for them. In particular, this answer is unavailable: they are perceptually indistinguishable because they share the same phenomenal look. That answer is unavailable if it presupposes there is a common phenomenal character or feature that both kinds of experience share.

With this in mind, let's look at what we might call a disjunctive theory of action. What is the view that the disjunctive theory of action is opposing? That rejected (by me, anyway) theory, which for brevity I shall simply call the non-disjunctive theory of action, also assumes a type of commonality, but in this case a certain sort of commonality between actions, intrinsic events, and mere events (compare: veridical perceptions and mere hallucinations). First, we need two pieces of terminology: an intrinsic event and a mere event.

In what follows, I intend for what I say to be neutral between so-called austere and prolific theories of act identity. My own prolific terminology is based on the assumption that plurality is often in the actions themselves and not just in the descriptions, so that when I kill the Queen by shooting her, I count my killing of her and my shooting of her as two actions, not two descriptions of one action. But for those who see the plurality only in the description and not in the action, I believe that everything I have to say in what follows can be rewritten using the austere terminology.

\section{INTRINSIC EVENTS AND MERE EVENTS}

What is an intrinsic event? Suppose an agent a-ed, where his a-ing is a token action (of type A). On one view of the matter, but not one that I accept, at least not for all cases of action (and not for all senses of the word 'event'):

(2) 'Someone a-ed' logically entails 'there was a token event $\mathrm{e}_{\mathrm{a}}$ of type $\mathrm{E}_{\mathrm{A}}$ '.

Jennifer Hornsby (1980), limiting her claim to actions described by transitive verbs, holds that there is an inference from ' $a V_{t} b$ ' ('a moved his finger') to ' $b V_{i}$ ' ('his finger moved'). ${ }^{4}$ David Hamlyn (1990: 130), evidently without limiting the claim to cases of action described by transitive verbs, says that "it is undeniable that, when we make a bodily movement [that is, when we act], a bodily movement in the intransitive sense [an event] occurs; when we move an arm certain arm movements take place." So, for example, if someone bent his finger, then ' $e_{a}$ ' stands for a token occurrence of the event type, a bending of his finger. I shall sometimes refer to the token action as 'his

4 Jennifer Hornsby (1980: 2) thinks of an action as what makes a sentence with the form 'aVTb' true ('Simon moved his hand'), and an event as what makes a sentence with the form 'bVi' true ('Simon's hand moved'). 'a' names a person, 'b' a bodily part, 'V' stands for a verb, and the subscripts 'I' and ' $T$ ' for intransitive and transitive occurrences of the verb respectively. 
$\mathrm{a}_{\mathrm{e}}$-ing', to mark the fact that token event $\mathrm{e}$ is meant to be the event whose existence is supposedly entailed by the a-ing.

Different writers use different terms for this event, ' $e_{a}$ '. Von Wright (1977: 39-40) calls it 'an event-result', and Maria Alvarez and John Hyman (1998: 233) adopt his terminology. Davis (1979: 5) calls it 'a doing-related event'. Bishop (1989: 105) says that it is the event that is 'intrinsic' to the action. Others have called it 'the associated event'. The intransitive sense of the verb describes the intrinsic or associated event. I shall follow Bishop's terminology. Actions, including basic actions on this view (more on basic versus non-basic actions below), can be 'paired' with intrinsic events. On this view, if an action occurs, it is necessary that the intrinsic event does.

Of course, Hornsby does not say that all intuitively action-verbs are transitive, and indeed many are not. The verb 'ran', for example, has both a transitive and an intransitive sense, and both senses indicate action. In the intransitive sense, in reply to 'how did you get there?', I can reply: 'I ran'. This running of mine is an action, even though 'ran' is intransitive in this usage.

For any specific action, how can one determine which is its intrinsic event? In the cases that I will discuss, the pairing of action and intrinsic event is obvious and unproblematic, since the act-description and the event-description are closely grammatically related: my moving of my finger and my finger's moving; my raising of my hand and my hand's rising. But there are cases which are not so obvious, and this is especially true in the case of action verbs like running, speaking, or spitting, which are intransitive or have an intransitive sense, because the obvious grammatical transformations are unavailable. If I run, the event intrinsic to this running is something like: my legs moving in such-and-such characteristic way. ${ }^{5}$

If this logical or conceptual entailment were to hold, as (2) asserts, the metaphysical nature of the relationship between basic action and intrinsic event is still open in many ways, and my use above of 'pairing' was meant to be vague and hence neutral in this regard. The fact of that entailment is compatible, for example, with the relationship between token action and its intrinsic event being metaphysically contingent. Here are some possibilities for that relationship:

(3) The action, his $a_{e}$-ing, causes its intrinsic event, $e_{a}$.

(4) The event, $e_{a}$, is metaphysically or de re necessary but insufficient for the action, his $\mathrm{a}_{\mathrm{e}}$-ing. For instance, the event might be a proper part of the action.

(5) The action, his $a_{e}-i n g$, supervenes on, but is not identical to, the event $e_{a}$.

(6) The action, his $\mathrm{a}_{\mathrm{e}}$-ing, is identical to the event, $\mathrm{e}_{\mathrm{a}}$.

It is easy to miss the fact that the entailment mentioned for example by Hornsby and Hamlyn is consistent with there being only a causal and hence contingent relation between basic action and its intrinsic event. ${ }^{6}$ The necessity required by the entailment might only be de dicto, arising from the ways in which the cause and effect are described. Just as 'the cause of b caused b' can be a metaphysically contingent causal

5 Davidson noted this fact about 'walks'. Quoted in Bach (1980: 114-20).

${ }^{6}$ I think it is easy to miss, because I once missed it. See Ruben (2003: ch. 2). 
claim ('the cause of b might not have caused b'), despite the de dicto necessity that arises from the descriptions used for cause and effect, so too 'his $\mathrm{a}_{\mathrm{e}}$-ing caused the event $e_{a}$ ' ('His bending of his finger caused his finger to bend') could be a genuine causal claim, on (3) at least, for the same reason.

(3) is dualistic, in the sense that it counts the action and the intrinsic event as two distinct existences. (6) is monistic, in the sense that for it there is only one item, describable as either an action or an intrinsic event. (4) and (5) represent a sort of compromise, since for these views there are not two distinct existences and yet there are two non-identical ones.

(3) is the view of Jennifer Hornsby (1980) and Paul Pietroski (2002), and echoes an earlier view of Pritchard's (1949). For Hornsby, this is summed up in the claim that "movements cause the body to move $_{\mathrm{i}}$. And actions are movements $s_{\mathrm{t}}$ (1980: 13). Pietroski says of basic actions:

[I]f Nora moved ${ }_{t}$ her finger, then Nora's action caused the moving $g_{i}$ of her finger. Her action caused the finger motion, just as Nora's action causes the melting $\mathrm{i}_{\mathrm{i}}$ of the chocolate. A similar treatment of 'raised ${ }_{t}$ ' suggests that if Nora raised ${ }_{t}$ her hand, her action caused the rising ${ }_{i}$ of her hand. (2002: 35)

Actions, for Hornsby and Pietroski, are 'internal' tryings (or, for Pritchard, willings) which cause external bodily movements and, via those bodily movements, other, nonbodily motions in the external world. 'Nora's moving of her finger' is the name of a basic action, a trying. (Of course, on their 'austere' view of act identity, lots of other descriptions might also be true of the trying, typically, physical action descriptions.) 'The moving of Nora's finger' is the name of an external bodily event. As they sometimes say, actions like Nora's moving of her finger are inner causes of external motions like the moving of Nora's finger.

(6), on the other hand, is claimed by many causal theories of action. If one holds that actions just are events non-deviantly caused by prior rationalizing mental states, then the action, his bending of his finger, just is the event, the bending of his finger, if the latter is so caused. The view is common and well-known. There are also many objections to it, some of which I have set out at length elsewhere (Ruben 2003), but which I do not rehearse here.

The simplest way in which to understand (4) is to construe the action to be the combination or mereological sum of his $\mathrm{a}_{\mathrm{e}}$-ing and its intrinsic event, $\mathrm{e}_{\mathrm{a}}$. If, for example, his $\mathrm{a}_{\mathrm{e}}$-ing is a mental item of some sort to be determined (but not itself the whole action), the action commences when that mental item occurs and terminates when the intrinsic event, $e_{a}$, finishes. In that sense, the intrinsic event would be a part of the larger action.

There is an assumption common to all four positions, (3)-(6):

(7) All physical actions, including actions like my moving or raising of my hand or my bending of my finger, have events intrinsic to them.

Once (7) is accepted, the question addressed by (3) - (6) arises, namely, the relationship between actions and their intrinsic events. 
Now for the second piece of terminology. What is a mere event? A mere event is a token event which is not intrinsic to any action. So, from the fact that a token mere event of type $\mathrm{E}$ occurred at $\mathrm{t}$ involving an agent's body, and no other token event of type E involving that agent's body occurred at the same time, it follows that that agent performed at $\mathrm{t}$ no token action of type $\mathrm{A}_{\mathrm{E}}$. Note that the concept of a mere event (like the idea of an intrinsic event) requires the prior concept of an action, since it is characterized by being an event that is not intrinsic to one.

Mere events include events like the explosion of a volcano, the collapse of a star, the gravitational pull of the moon, or the lapping of the waves. No tokens of those event types are going to count as events intrinsic to any action. One might dispute whether it is necessarily true or only contingently true that no tokens of these types are intrinsic events, but on either view, it is at least a truth that none are.

But the tokens of other event types sometimes are mere events and sometimes are events intrinsic to an action. The death of the Queen can be a mere event when she dies of natural causes, but can be an event intrinsic to my action if I kill her.

So too it is with the waving of my hand or the moving of my left arm. When my left arm moves or my left hand waves as a result of a neurological spasm, these are mere events. On the other hand, I may wave my left hand by moving it with my right hand. When I bring about the waving of my left hand or the moving of my left arm by manipulating my left hand or arm by my right hand, then the waving of my left hand and the moving of my left arm are events intrinsic to my (non-basic) action, my waving of my left hand or my moving of my left arm. (I use the idea of basic and nonbasic action at this point, relying on readers' intuitions: an action of mine is not basic if I do it by doing something else.)

\section{A DISJUNCTIVE THEORY OF ACTION}

Let's accept that there are events, although even this is itself hardly beyond dispute. ${ }^{7}$ Both mere events and intrinsic events belong to the same fundamental type, being an event; or, (modulo some controversial assumptions about event identity) what is an intrinsic event could have been a mere event, even if the converse is not always true. There are many competing accounts in the literature of what it is for something to be an event; what I say here is intended to be neutral between all such accounts. Jonathan Bennett (Bennett 1988: chs. 4-8) offers an excellent survey of some of those options. I make commitments about the concept's extension, but certainly not about its intension. I have no, and hence offer no, analysis of eventhood.

If (2) were true, whenever there is an action, there would be an event intrinsic to that action. So, just as on a non-disjunctive theory of perception, in the cases of both a veridical perception and a hallucination, the appearance or look is meant to be the same and common to both, so too on a non-disjunctive theory of action, we could say

7 See for instance Horgan (1978: 28-47). 
that in the case of both a mere event and an action, something belonging to the same fundamental type occurs and is common to both. If a mere event occurs, trivially, an event occurs; if an action occurs, then, on (2), an event intrinsic to that action occurs, so an event occurs (even if that last event is not identical to the action). There is a kind of commonality between actions and mere events, since in either case something of the same fundamental type occurs, namely an event.

Let me now prepare the grounds for introducing a disjunctive theory of action. We broke off the discussion of (2) above, wondering about the relationship between actions and intrinsic events. If these actions and their intrinsic events are neither identical nor non-identical (because I think all the options canvassed thus far are unattractive), what other option might remain open to us, for understanding the relationship between actions and their intrinsic events?

I think a possible suggestion is this: to deny the inference claimed by (2), and thus to deny (7). So, pace (2) and (7), there is no element common to the occurrence of both mere events and basic physical actions, via the events allegedly intrinsic to the latter, because there are no such events in this case. That is, I claim that in an important sense there is no such logical or conceptual entailment as (2) claims. We should deny the existence of any such intrinsic events, in certain (but not all) cases of physical action. Unlike (6), which is a reductionist theory, I am proposing what might be thought of as an eliminativist one. For cases of basic physical action, I want to eliminate intrinsic events. By denying their existence, I thereby deny the commonality assumption for basic physical actions and events.

For these cases of physical action, namely, basic ones, nothing occurs that is fundamental and in common to both these actions and events. The question of the nature of the relationship between basic physical action and intrinsic event would then never even arise, just as: if we deny the existence of a look common to veridical perception and hallucination, the question of the relationship between appearance and object would never even arise. I am not just denying that the basic action and its intrinsic event are identical. I deny that any such intrinsic event occurs at all, even one necessary but insufficient for the basic action; a fortiori, if there is no intrinsic event, it can't be identical to anything. ${ }^{8}$ No identity of basic action and intrinsic event, and no duality either, because no intrinsic event.

Other philosophers have also denied (7). For example, Hugh McCann (1998) says that the denial of events intrinsic to basic actions is essential to halt a vicious regress. Wittgenstein asked: "What is left over if I subtract the fact that my arm goes up from the fact that I raise my arm?"9 Wittgenstein's question can arise, says McCann, whenever an action has an event intrinsic to it. If an action (my killing of the Queen) has an event intrinsic to it (namely, the Queen's death), which intrinsic event is itself

8 Someone might confuse my thesis with the question of inactions, omissions, and forbearances. Most theorists count these as actions. I suppose that, if it is an action, my intentionally keeping quiet is a basic action, since it is not an action I do by doing something else. Whatever we might decide about such cases of 'negative' action or inactivity, my claim is about 'positive' action that evinces activity.

9 Wittgenstein's question is quoted in McCann (1998: 75). All my page references are to McCann (1998). 
brought about by a more basic action of the agent (my pulling of the trigger), or by an event intrinsic to that more basic action, we shall finally get to an action which can't be given this sort of analysis, on pain of infinite regress. That action we might call a basic action. That action will fail to have an event intrinsic to it. (Of course, there are in principle other ways to halt the regress that perplexed Wittgenstein, which McCann does not consider.)

As McCann (1998: 87) says: "If there is no result [intrinsic event] to be distinguished from the action, there can be no question as to what makes it a result." So McCann and I would both deny that basic actions have events intrinsic to them. Call such basic actions 'pure'. Indeed, this provides part of the account I would give for the basicness of an action: an action is basic only if it is pure, and a physical action is basic iff it is pure. McCann claims to have found actions that have no events intrinsic to them, and hence which stop Wittgenstein's regress, but only in the case of certain mental acts: for example, acts of thinking and willing (to which we might add tryings, on some views). "That acts of thinking do not have results [events intrinsic to them] means there can be no action-result problem about thinking" (McCann 1998: 87).

McCann and I agree that (7) is false. I could also agree that there are such things as pure mental actions (although nothing in this essay requires that view). My disagreement with McCann is that I do not think that we have to hold that there is pure mental action, in order to find cases of basic action. Some physical actions are pure as well. I think that there are basic physical actions that are pure, that have no events intrinsic to them. (The fact that there may be some pure mental actions, but which may not count as basic actions, is why purity of an action, for me, cannot be a sufficient condition for basicness simpliciter).

Since for McCann these willings and thinkings (or other mental actions like them) are the only pure actions there are, he must claim that every action is done by or is caused by (or, on an 'austere' view of act individuation, is identical to) an act of willing or thinking or similar. On this view, it is from willing or thinking that all other cases of agency stem. It locates basic action 'inside' the agent, in his mind. McCann's account, like Pritchard's, is Cartesian. If Hornsby locates actions inside the brain or nervous system, her view would be best understood, I think, as a physicalist solution to a Cartesian problem. My view locates (at least some) pure, basic action at the bodily surface of the agent. We need not, on my theory, be driven inside the agent to find an act of will or a brain event as a stopping place to account for action. ${ }^{10}$ My account has no need to solve the apparently Cartesian location problem for action. My account is Aristotelian in its inspiration. ${ }^{11}$ I find purity at the surface of an agent's body.

Presumably, assuming that there are lots of things an agent does, there will have to be, on McCann's theory (and on Pritchard's), an awful lot of willings or other pure mental acts around as well: "bodily actions typically involve the mental activity of

10 The only discussion I know of this occurs in Candlish (1984: 83-102).

11 Or even Marxian. See Marx (1965) for a view of action which, at least under one interpretation of those cryptic statements, I find congenial. The influence of Aristotle on Marx, probably via Hegel, is profound. 
volition or willing and ... this activity is . . the basic activity we engage in when" we physically act (McCann 1998: 75). Other things being equal, it is unattractive to have to hold that, on every occasion on which I physically act, on every occasion on which, for example, I bend a finger, raise my arm, or open my hand, I am engaging in some mental act, as this view requires. Or, to word substantially the same criticism differently so that it will fit the Hornsby-Pietroski 'austere' view of act individuation: it is unattractive (so I say, anyway) to have to hold that on every occasion on which I physically act, it is also true that my act is a trying.

So I hold, contrary to McCann:

(8) Some physical actions are pure, and have no event intrinsic to them.

What do I mean when I say that when a basic physical action occurs, no event intrinsic to that action occurs? To repeat, my view is that, when Nora moves her hand (and not by doing something else), there is in one sense no such event as her hand's moving that occurs. All that there is, is the action. What do I mean by: "there is in one sense no such event as her hand's moving that occurs"? Why the qualification, "in one sense"? I think that the philosophical literature uses the idea of an event, and specific event type names, like the moving of a hand, ambiguously and we need to take account of this ambiguity in order to see the force of the disjunctive theory of action.

If we agree that when a basic physical action occurs, no event intrinsic to it occurs, we can still ask this question: does any event occur when a basic physical action does? Even supposing (8) to be true, the answer to that question could still be in the affirmative, in the following way. One might hold that actions are a type of event as a result of what is in effect a classificatory decision. Let's call this the classificatory or wide concept of an event. Actions may simply be classified as a subclass of events, by stipulation of the concept's extension. The wide concept of an event has, in its extension, mere events (like the eruption of Vesuvius), events intrinsic to non-basic actions (like the death of the Queen when I kill her by shooting her), and actions themselves, basic and non-basic. This concept of event is compatible with a disjunctive theory of action.

Similarly, the event type, the movings of a hand, taken in this wide or classificatory sense, will have the movings of a hand which are mere events (for example, my hand moves as a result of your pulling it), the movings of a hand which are intrinsic to non-basic actions (for example, my hand moves because I move it by twisting it with my other hand), and basic actions (for example, I move my hand but not by my doing something else), all in its extension. I do not think that this wide or classificatory sense of event is a sense merely invented or stipulated by me. Many philosophers rather uncritically take actions to be a subset of events, without argument, and when they do this, they are best interpreted as using the wide or classificatory sense of event in making that claim.

When they use the concept of an event in this wide way, I don't think it is (2) and its likes that they have in mind. They are not arguing that actions are events because they are identical to their intrinsic events; that would require a substantive 
philosophical argument. They are simply, and often uncritically, classifying actions as a type of event in their own right. There would be no philosophical 'finding out' if actions are events on the wide concept. They would be, by 'definition', events. Since this is only a question of classification, and not one of substantive philosophy, no honest philosophical labour is required for this result. On this wide concept of event, if an action occurs, even a basic physical action, it follows trivially that an event occurs - namely the action itself — but it does not follow that an event intrinsic to the action does.

So this introduces a complication in the comparison between disjunctive theories of perception and action. One disanalogy between the disjunctive theory of perception and that of action is that in the latter, there is an ambiguity for which there is no counterpart in the former: the concept of an event and the concept of (some) specific event types. In contrast to the wide or classificatory concept of an event described above, there is a narrower, more philosophically specialized sense of that concept. In that second sense, only mere events and events intrinsic to actions (if and when there are such) are events. In this narrow sense, actions would count as events only if identical to their intrinsic events.

As I said earlier, mere and intrinsic events are of the same fundamental kind. The extension of the narrow concept of event includes these two kinds of items. The various different accounts of eventhood in the literature are well-known and the reader can plug in at this point, for this sense, whatever might be his favourite account. It seems to be that many of the philosophers who have held that actions are not events mean that they are not events in this second sense. ${ }^{12}$ Both concepts of event, the wide or classificatory and the narrow, seem to be legitimate and useful.

On the non-disjunctive view of action that I reject, what would be 'common' to both mere events on the one hand and to actions (which on this view would have intrinsic events) on the other would be the occurrence of an event in this narrow sense. If basic physical actions are to be identified with their intrinsic events, as (6) claims, then the former after all do fall into the extension of the narrow concept of an event since the latter do. If basic physical actions have intrinsic events but have a relationship with them other than one of identity (for example, as (3)-(5) propose), the commonality is different, but still a type of commonality: when a basic physical action occurs, an event in the narrow sense, intrinsic to that action, also occurs, an event to which the basic action is related but with which it is not identical.

\footnotetext{
12 See for example Bach (1980: 114-20). I find Bach's view hard to understand. If actions were causings, and causings are 'instances' (his word) of a relation, I do not see why causings would not count as individuals. Bach uses as illustration the idea of a round, red ball, and says that it would be ludicrous to ask how many instances the ball displayed. I am not so sure. If Iago loves Desdemona and Romeo loves Juliet, there is a perfectly good answer to how many lovings, or instances of love, are under discussion: two. Similarly, if there are two red balls, there are two instances of the colour, red. I see no objection to taking instances seriously, as individuals. Bach thinks that actions are causings, and that causings are not events. Causings, for him, are instances of a relation, and can neither be quantified over nor be individuated. For Alvarez and Hyman (1998), for various reasons they give, actions are not events but there is no suggestion on their view that actions do not count as a kind of individual, parallel to but different in kind from events.
}

as a kind of individual, parallel to but different in kind from events. 
On the other hand, one can express my disjunctive view of action as an exclusive disjunction, with three disjuncts (and, in terms of truth-making, the disjunction is to be read right-to-left):

(9) $\mathrm{i}$ is an event (in the wide, classificatory sense) iff $\mathrm{i}$ is an action or $\mathrm{i}$ is a mere event (in the narrow sense) or $\mathrm{i}$ is an event (in the narrow sense) intrinsic to an action.

Since I have characterized mere events simply as the complement class of intrinsic events, there is good reason to take (9) as exhaustive as well as exclusive. But if there is someone who thinks there is another disjunct that can be added to (9), I have no reason to resist that move.

On the disjunctive view represented by (9), from the fact that no token mere event of type E occurs to an agent's body at $t$, it does not follow that the agent has not performed at $t$ a token action of type $A_{E}$ (recall that the occurrence of suitable mere events actually excludes corresponding action). And from the fact that no mere event of type $\mathrm{E}$ and no intrinsic event of type $\mathrm{E}_{\mathrm{A}}$ has occurred to an agent's body at $\mathrm{t}$, it does not follow the agent has not performed a basic action of type $\mathrm{A}$ at $\mathrm{t}$.

One might describe (9) as a disjunctive theory of events, rather than of action, and surely it is at least that. But just as the disjunctive theory expressed by (1) can be called a disjunctive theory of perception rather than of experience, because it is a response to what is often called the problem of perception, so too (9) might be called a disjunctive theory of action rather than of events, because it is a response to what is often called the problem of action. Instantiations of (9) will apply for some specific event types as well as for the general concept of an event. Since (9) is intended as an exclusive disjunction, no event in the narrow sense occurs if a basic action does, and hence a fortiori no such event is common to both the case of basic action and the occurrence of an event in the narrow sense.

Why should we accept (9) and deny the existence of events intrinsic to basic physical actions? What counts in favour of this option, relative to the options sketched in (3)-(6)? Suppose (9) were not superior in any way to the other choices. All the same, I believe that it is important to show that this view can occupy a perfectly acceptable position in the logical space of alternatives. I know of no other place in which the purity, in my sense, of some physical actions is put forward as an alternative position.

But I do think that the main arguments for (9) are twofold: (a) I know of no consequences of (9) that raise insoluble difficulties, and (b) the greater unacceptability of the alternatives - either the identity or the duality of basic action and intrinsic event. All the alternative theories of action seem to have some unintuitive consequences. The location of action inside the agent's brain or mind is prima facie implausible. On the other hand, the identification of actions with bodily events robs us of the very activity of actions; it is hard to see how action can be constructed from the passivity of what just happens. (9) has neither of those disadvantages. Coupled with my disarming of what might be thought to be its implausible consequences, I regard the case I put forward, for the acceptance of (9) and the denial that there are events intrinsic to basic physical actions, as a strong one. I will not, in this essay, rehearse in any detail the points that seem to me to constitute a strong case for (b), points that I have made elsewhere (Ruben 2003). 
So either a person basically moves his hand or his hand moves (and this is an exclusive disjunction). The first is a basic action with no event intrinsic to it; the second is a mere event or an event intrinsic to his non-basic action (he may move his one hand by using the other to move it). So if I move my hand (as a basic action), it is false that my hand moved or that it changed place (in the narrow sense), only true that I moved it or that I changed its place. ${ }^{13}$ On the flip side, if the event of my hand's moving or changing place does occur (in the narrow sense), then it is false that I basically move my hand. When p moves his hand, or when he changes its place, and these are basic actions, there is no event that occurs intrinsic to that basic action. Other events may occur, and it may be that his basic moving of his hand is itself an event as well as an action, in the wide, classificatory sense, but there is no hand moving which is intrinsic to my moving of it, and hence no hand moving in the narrow sense.

Does this view have any unacceptable consequences? There are two pieces of data, (10) and the inferences between (11), (12), and (13), which I want to try to account for and which appear to be inimical to my view.

The first piece of data is this. Is it really false that when I move my hand, my hand moves? Surely an observer, who sees me move my hand, may say:

(10) "I am sure that I saw his hand move. Whether he moved it, or someone or something else did, I don't know."

What might the thought be behind (10)? The observer may be in doubt whether he has observed an action, even a basic action, or a mere event (say, the hand's moving as a result of a nervous spasm). But if the observer can be in doubt, then the two possibilities that (10) canvasses must be perceptually indiscriminable, and that must be because whatever it is that is observed is 'common' to both possibilities. In either case, whether it be his hand moving or his moving of his hand, what the observer would have observed is the same item, an event, and that item is 'neutral' between the cases of basic action, intrinsic event, and mere event. If what is observed is a mere event, then an event is observed. If what is observed is a basic action, then what is observed is also an event - but in this case, an event intrinsic to the basic action. Construing the data in this way will certainly refute my disjunctive theory by finding an element common to basic action, intrinsic event, and mere event.

The disjunctive theory of action is better placed to deal with this issue than is the disjunctive theory of perception. What the disjunctive theory of action must say is this: from the fact that a basic physical action, an intrinsic event, and a mere event

13 Fiona Macpherson has suggested the following. There might be a straightforward case in which this is the natural description: suppose I am on a train travelling in direction A at $10 \mathrm{mph}$ and that I move my hand in the direction opposite to A at $10 \mathrm{mph}$. In terms of objective location my hand has not moved. However, it does seem right to say that I moved my hand. This seems not really to be especially relevant to action and event, for the same thought can arise in the case of two mere events: can there be a mere moving of my hand without a mere changing of its place (in the same circumstances she describes, for example)? The thought is an interesting one and surely much about its answer depends on questions concerning absolute versus relative space. But as it is not particularly a thought experiment relating to the relationship between actions and events, I don't think it will help me here. 
might all be perceptually indistinguishable, it does not follow that they must have something philosophically significant in common to explain that indistinguishability. Of course, they might have these three features in common: being (or entailing the existence of something which is) perceptually indistinguishable from an action, from an intrinsic event, and from a mere event. But, as in the case of being perceptually indiscriminable from a veridical perception and from a hallucination, these commonalities are trivial.

Is there anything else that a disjunctive theory of action could say? Could it explain why one of these items might be mistaken for another, in the way in which hallucinations might get mistaken for veridical perceptions? A disjunctive theory of action can say more, because it can say exactly what a disjunctive theory of perception cannot say: a person may be in error or doubt or confusion about whether he is observing a mere event, intrinsic event, or action, because of the common look shared by all three sorts of occurrences. They may have nothing philosophically significant in common that would refute (9), but they can all have a certain look in common. They look alike.

To that degree, actions and events are like gold and fool's gold, or water and twinearth water. Gold and fool's gold look alike, and water and twater look alike, but phenomenological appearance is no guide to philosophically or scientifically significant classification. This is exactly what a disjunctive theory of perception cannot say, since it is dealing precisely with phenomenal character itself, and not the significant features of things beyond the appearances. Phenomenology is a bad guide to kindhood, at least for minerals, compounds, events, and actions. Two observationally or perceptually indiscriminable items, for example an action and a mere event, may be perceptually indiscriminable because they look alike, yet be of fundamentally different kinds.

We have been speaking until now of how an action, an intrinsic event, and a mere event might all be perceptually indiscriminable to an external perceiver of actions and events. But the perceptual indiscriminability for the disjunctive theory of perception is indiscriminability by the perceiver of his own experiences or states. Is there an analogue to this for a disjunctive theory of action? Various things may happen to, or be done by, an actor: he might raise his arm as a basic action; he might raise his arm by his doing something else; his arm might rise without him raising it at all. Might he himself be unable to discriminate amongst those possibilities, or anyway between the first and third, whatever the case might be for an external observer?

William James (1890: 489-92) cites two examples of just such a case. (a) Professor Strümpell's description of his "wonderful anaesthetic boy": "Passively holding still his fingers did not affect him. He thought constantly that he opened and shut his hand, whereas it was really fixed." (b) Dr Landry's account of a blindfolded patient: "If, having the intention of executing a certain movement, I prevent him, he does not perceive it, and supposes the limb to have taken the position he intended to give it."

If opening and closing one's hand or "executing a certain movement with a limb", at least on the occasions being considered, are basic physical actions, both Strümpell's and Landry's cases are ones that are or can be made pertinent to our discussion. In both cases, the person has done nothing, or anyway executed no physical action, but 
falsely believes that he has done something, and indeed falsely believes that he has a-ed, where 'a-ing' is a basic physical action description. That is, the agent believes that 'my a-ing' refers to his token basic physical action when it in fact refers to nothing. The wonderful anaesthetic boy falsely believed that he opened his hand; Landry's patient falsely believed that he had executed a certain movement with a limb. In both cases, no physical action occurred, basic or otherwise.

The examples would make the same point if, for example, the wonderful anaesthetic boy's hand had been opened and shut after all, not by him, but rather by some force made invisible to him. The boy, as long as it is not observable by him that he was not responsible for his body's movement, might falsely come to believe concerning some mere physical occurrence involving his body, perhaps the opening and closing of his hand, that it was a basic action of his, when it in fact was not. James's counterexamples do not have to concern beliefs about action rendered false by total lack of movement; the counterexamples could also concern beliefs about action rendered false by the occurrence of mere bodily movements that are not actions.

So not only can the agent himself falsely believe that he is basically physically acting when nothing relevant occurs at all. Concerning some mere event or happening, perhaps the opening of his hand, a person could falsely believe that that mere event is his basic physical action (his opening of his hand) when it is not an action at all. So an agent might not know which of the two disjunctive situations, action or mere event, that he is in, just as a perceiver might not know which of the two disjunctive states, veridical perception or hallucination, that he is experiencing.

In perception, a perceiver might mistake hallucinations for veridical perceptions but could also mistake veridical perceptions for hallucinations. The cases cited by James show or can be made to show that an agent might mistake mere events for his actions. Could an agent also mistake his actions for mere events? I believe that this is also possible, and have described such cases elsewhere (Ruben 2003: 218-19).

The second piece of seemingly recalcitrant data is this:

(11) 'Simon moved his hand' entails

(12) 'Simon's hand was moved by Simon.'

And (12) 'Simon's hand was moved by Simon' surely entails

(13) 'Simon's hand moved.' 14

So doesn't the action, his moving of his hand, entail that there was an event, the moving of his hand, after all? The second inference looks as if it is merely a case of simplification. If so, there is surely no exclusive disjunction, since from the truth that Simon moved his hand, it follows that there was a moving of his hand.

I want to argue that there is a sense of 'moving' in which the inference goes through and a sense in which it fails, but in that first sense the success of the inference does not damage my view. The sense of 'moving' for which it fails is the narrow sense; the sense in which it goes through is the wide or classificatory sense.

14 Berel Lerner pointed these inferences out to me. 
In fact, there is a missing step in the argument above. It is this: (12) entails (12a) 'Simon's hand was moved', by simplification. (12) and (12a) are both about action, even though they are in the passive voice. (12a) is of course elliptical, since anything that was moved was moved by something or someone.

That there is a sense in which the inference is valid hardly needs arguing. It will surely strike the reader as obvious. We can allow that the inference is valid if we take movement or event in the wide or classificatory sense, but in that sense the admission will be harmless to my position. In the wide sense, (11), (12), (12a), and (13) are all made true by actions, even though (12) and (12a) are in the passive voice; if (13) uses 'moves' in the wide sense, what makes (13) true is the truth of the action disjunct in that disjunction which gives the extension of event or movement in the wide sense.

But let me try to convince the reader that there is a sense of 'moving' in which the inference fails and is invalid. If (13) uses 'move' in the narrow sense, I would say that in the case in which his hand was moved by the agent, (12), and hence in which his hand was (elliptically) moved (12a), (13) does not follow. It does not follow that it moved (in the narrow sense), for there is no event, a moving of the hand, in the narrow sense, which could make (13) true in that sense.

So, if Simon's hand was moved by him, it did not move in the narrow sense. (12a) does not entail (13), in the narrow sense of event or the narrow sense of the moving of his hand.

\section{REFERENCES}

Alvarez, M. and Hyman, J. (1998) 'Agents and Their Actions', Philosophy, 73: 219-45.

Bach, K. (1980) 'Actions Are Not Events', Mind, 89: 114-20.

Bennett, J. (1988) Events and Their Names, Oxford: Oxford University Press.

Bishop, J. (1989) Natural Agency, Cambridge: Cambridge University Press.

Candlish, S. (1984) 'Inner and Outer Basic Actions', Proceedings of the Aristotelian Society, 84: 83-102.

Child, W. (1992) 'Vision and Experience: The Causal Theory and the Disjunctive Conception', Philosophical Quarterly, 42: 297-316.

Dancy, J. (1988) (ed.) Perceptual Knowledge, Oxford: Oxford University Press.

Davis, L. (1979) Theory of Action, Englewood Cliffs, NJ: Prentice-Hall.

Goodman, N. (2005) Fact, Fiction, and Forecast, Cambridge, MA: Harvard University Press.

Hamlyn, D. (1990) In and Out of the Black Box: On the Philosophy of Cognition, Oxford: Blackwell.

Hinton, J. M. (1973) Experiences, Oxford: Oxford University Press.

Horgan, T. (1978) 'The Case against Events', The Philosophical Review, 88: 28-47.

Hornsby, J. (1980) Actions, London and Henley: Routledge \& Kegan Paul.

James, W. (1890) The Principles of Psychology, vol. 2, London: Macmillan \& Co.

Lowe, J. (2000) An Introduction to the Philosophy of Mind, Cambridge: Cambridge University Press. 


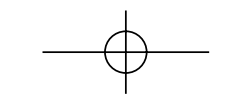

Theories of Perception and Action

McCann, H. (1998) 'Volition and Basic Action', in his The Works of Agency, Ithaca, NY: Cornell University Press, 1998: 75-93. [First published in Philosophical Review, 20 (1974): 451-73.]

McDowell, J. (1982) 'Criteria, Defeasibility, and Knowledge', Proceedings of the British Academy, 68: 455-79

Martin, M. G. F. (2004) 'The Limits of Self-Awareness', Philosophical Studies, 120: $37-89$.

Marx, K. (1965) The German Ideology ( $\&$ Addenda), London: Lawrence \& Wishart.

Pietroski, P. (2002) Causing Actions, Oxford: Oxford University Press.

Pritchard, H. A. (1949) 'Acting, Willing, Desiring', in his Moral Obligation, Oxford: Clarendon Press.

Ruben, D.-H. (2003) Action and its Explanation, Oxford: Oxford University Press.

Snowdon, P. (1980-1) 'Perception, Vision, and Causation', Proceedings of the Aristotelian Society, 81:175-92.

Wright, G. K. von (1977) Norm and Action, London and Henley: Routledge \& Kegan Paul.
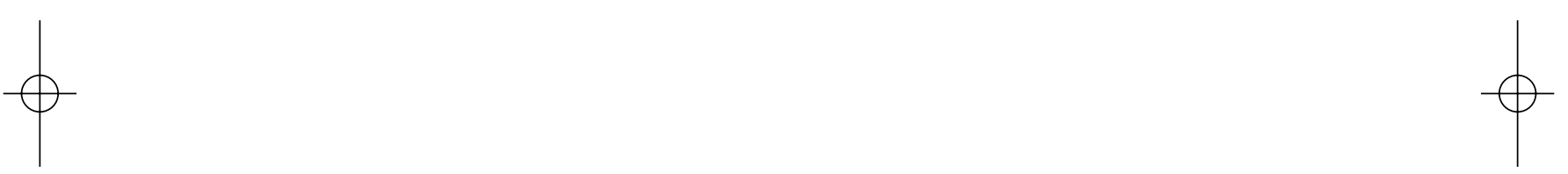